\title{
Mosquito community composition in South Africa and some neighboring countries
}

Anthony J. Cornel ${ }^{1,2^{*}}$, Yoosook Lee ${ }^{1}$, António Paulo Gouveia Almeida ${ }^{3,4}$, Todd Johnson ${ }^{4}$, Joel Mouatcho², Marietjie Venter ${ }^{4}$, Christiaan de Jager ${ }^{2}$ and Leo Braack ${ }^{2}$

\begin{abstract}
Background: A century of studies have described particular aspects of relatively few mosquito species in southern Africa, mostly those species involved with disease transmission, specifically malaria and arboviruses. Patterns of community composition such as mosquito abundance and species diversity are often useful measures for medical entomologists to guide broader insights and projections regarding disease dynamics and potential introduction, spread or maintenance of globally spreading pathogens. However, little research has addressed these indicators in southern Africa.
\end{abstract}

Results: We collected 7882 mosquitoes from net and light traps at 11 localities comprising 66 species in 8 genera. We collected an additional 8 species using supplementary collection techniques such as larval sampling, sweep-netting and indoor pyrethrum knockdown catches. Highest diversity and species richness was found in the Okavango Delta of Botswana and in South Africa's Kruger National Park, while the lowest diversity and abundances were in the extreme southern tip of South Africa and in semi-desert Kalahari close to the South Africa border with Botswana. Species composition was more similar between proximal localities than distant ones (Linear model $P$-value $=0.005$ ). Multiple arbovirus vector species were detected in all localities we surveyed (proportion of vector mosquito numbers were $>0$. 5 in all locations except Shingwedzi). Their proportions were highest (> 90\%) in Vilankulo and Kogelberg.

Conclusions: Multiple known arbovirus vector species were found in all study sites, whereas anopheline human malaria vector species in only some sites. The combination of net traps and light traps effectively sampled mosquito species attracted to carbon-dioxide or light, accounting for $89 \%$ of the 74 species collected. The $11 \%$ remaining species were collected using supplementary collection techniques mentioned above. The diversity of species weas highest in savanna type habitats, whereas low diversities were found in the drier Kalahari sands regions and the southern Cape fynbos regions.

Keywords: Mosquitoes, Vectors, Arboviruses, Malaria, Shannon index, Diversity measures, Mosquito community composition

\section{Background}

Historic interest in the mosquitoes of southern Africa has largely been based on their role as vectors of human or animal disease. Malaria-associated morbidity and mortality was very high during the early decades of the 20th century [1-5] and gave rise to a disproportionately

\footnotetext{
*Correspondence: ajcornel@ucanr.edu

${ }^{1}$ Department of Entomology \& Nematology, University of California, Davis, USA ${ }^{2}$ UP Institute for Sustainable Malaria Control \& MRC Collaborating Centre for Malaria Research, Faculty of Health Sciences, University of Pretoria, Pretoria, South Africa

Full list of author information is available at the end of the article
}

large body of still-increasing literature on anopheline mosquitoes [6-13]. Outbreaks of arboviral disease, associated with high mortality in livestock, resulted in sustained research on non-anopheline mosquitoes [14-22], with an associated surge in publications relating to regional surveys commencing in the 1950's and 1960's for arboviruses affecting humans [23-29]. In more recent decades the rapid spread and increasing global challenge posed by mosquito-borne viruses, such as West Nile, Zika and others, spurred further publications on mosquitoes [30-33].

The overwhelming majority of the mosquito literature for southern Africa addresses mainly aspects of identification, 
taxonomy or classification [34-40], vector potential or status in one way or another [14,31,41-46], or discussion of specific species in relation to insecticide resistance or other aspects of disease control [47-53]. Aside from the breeding biology of some species [54-57], little work has been done on the general ecology and compositions of mosquito communities in southern Africa. Much of the earlier knowledge is captured in summary overviews in the standard reference volumes on anophelines [58, 59] and culicines [60]. Broadly speaking, the species composition and geographical distribution patterns of anopheline mosquitoes in southern Africa are better documented than for culicines, whilst abundance trends and diversity patterns for all mosquito groups have been largely neglected or undocumented.

The increase in frequency of arbovirus outbreaks and rapid spread of such diseases, as well as scale of the public health consequences [61-65], have given rise to multiple calls for countries globally to raise vigilance regarding arboviruses $[66,67]$ and an associated need to understand the population status of known or potential vector mosquitoes. This paper provides an initial assessment for understanding broad patterns of mosquito diversity, abundance and distribution in southern Africa. Most of the southern African landscape has been altered, due to human agricultural and settlement influences, but a few pockets of more pristine mosquito diversity attributes should still be found in designated National Parks and wilderness areas. For this study, priority was given to natural reserves so that mosquito catches would represent the historic 'natural' state of populations. Therefore our results would represent baseline species diversity data which future surveys could be compared to for assessing human impact in nearby areas of land use change. These studies are also broadly aimed to develop projections and models of where arboviruses are likely to establish and persist when mosquito vector and vertebrate host data are combined.

\section{Methods}

We limited the species diversity comparisons to one season to avoid inter-annual fluctuations by undertaking all the surveys within eight weeks, from multiple habitats, using predominantly net $\left(\mathrm{CO}_{2}\right.$ baited) and (white light + $\mathrm{CO}_{2}$ baited) $\mathrm{CDC}$ traps [68].

\section{Collection period}

Our surveys ran from late-January until early-April 2015, averaging three to four nights per locality. Much of the southern African region experiences summer rainfall from November to April [69]. Mosquito breeding also peaks during these hotter and wet months, so that most mosquito populations are at their highest levels from about January to mid-April. The Kogelberg Nature Reserve in the Western Cape is the exception, falling within a winter rainfall region. However, all the trapping locations in this Reserve were close to the Palmiet River and its fringing fynbos vegetation, which would be the primary source of mosquitoes independent of rain.

\section{Geographical distribution of study sites}

A priori selection of localities was aimed at sampling the widest range of biomes, land cover types and geographical spread within the available time and resource constraints, with an emphasis on South Africa, which is the focal country for studies on zoonoses by the University of Pretoria. Georeferenced locations and land-cover types of these localities are provided in Table 1 and Fig. 1, respectively. Locations where mosquitoes were captured were mainly savanna and grassland habitats, except for Vilankulo where some land cover consisted of croplands (Fig. 1).

We moved trap locations each night to cover as many different habitat types as possible and therefore get the widest possible range of species. However, within each locality, all the different trap locations clustered within an arbitrary $10 \mathrm{~km}$ distance (Euclidean distance) were collectively designated with one locality name (e.g. Kogelberg, Tswalu or Shingwedzi, etc.), whereas trap sites more than $10 \mathrm{~km}$ apart were recorded and named separately (e.g. Skukuza, Lower Sabie and Tshokwane).

\section{Collection methods}

We placed three net traps ([70], Fig. 2a) and three CDC white fluorescent light traps (Fig. 2b) each night, each baited with $\mathrm{CO}_{2}$ in the form of dry ice as attractant. Light traps were not deployed at the Mozambican sites, where we used $\mathrm{CO}_{2}$-baited net traps and also pyrethrum knockdown catches within rural dwellings (the latter results not used for analyses here, but mention is made of species collected for context). At other sites, traps were usually paired consisting of one net trap and one CDC trap that were placed within $100 \mathrm{~m}$ from each other, and each pair of traps was placed several hundred metres or several kilometres apart. CDC light traps were not used in Vilankulo and in Lower Sabie the CDC light traps failed because of battery charging problems and the catch nets falling off the traps.

Traps were placed and baited late afternoon, before dusk, and emptied before first light each morning. Mosquitoes were removed from within net traps using hand held aspirators and transferred into mesh-topped polystyrene cups, and the light traps by tying off the necksleeve of the collection bucket. All collections were killed within a few hours thereafter by freezing and immediately examined microscopically for species identification. Representative specimens were pinned as reference material and the remaining specimens grouped by species and frozen in liquid nitrogen for subsequent virus isolation assays. 


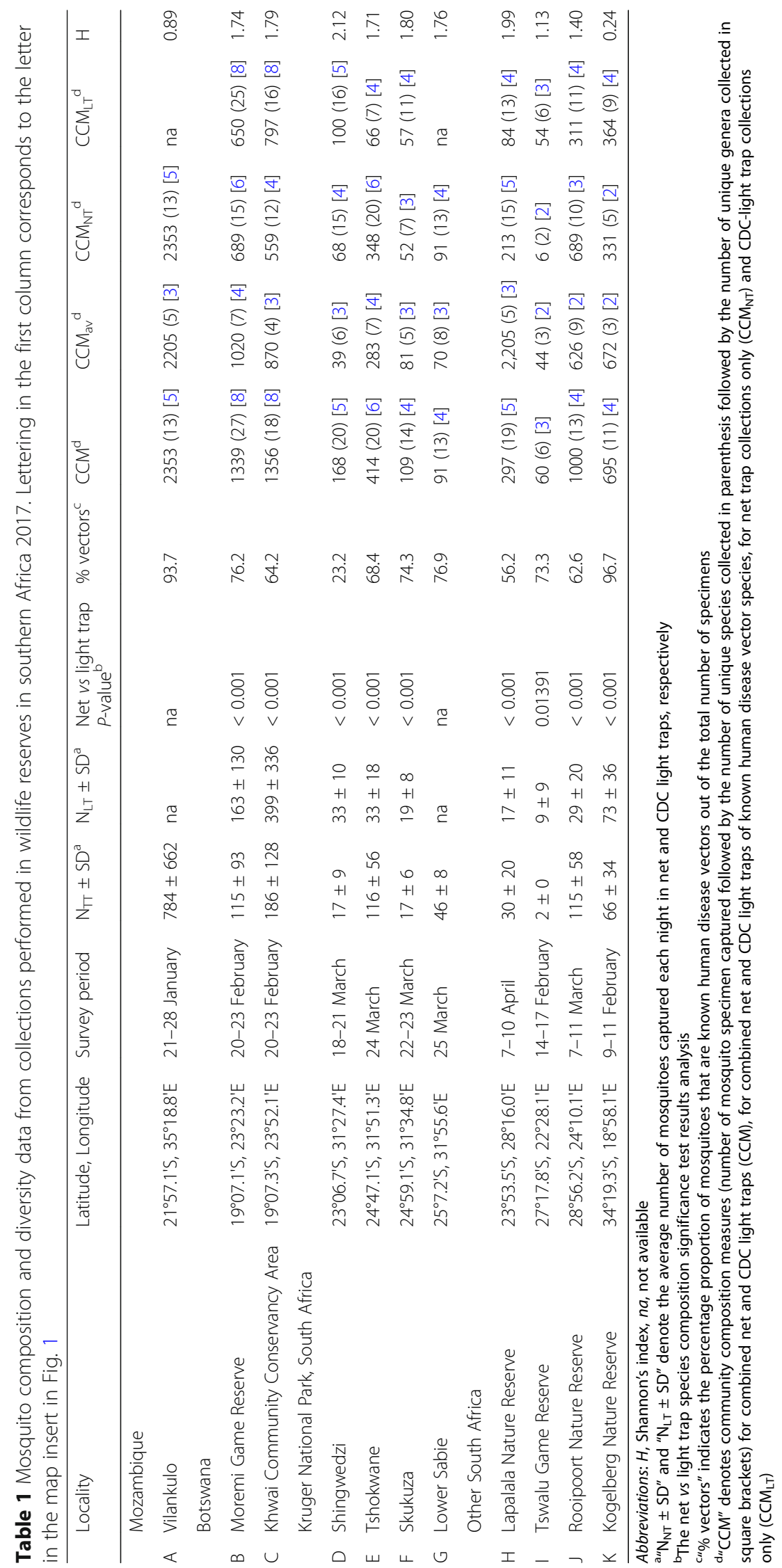



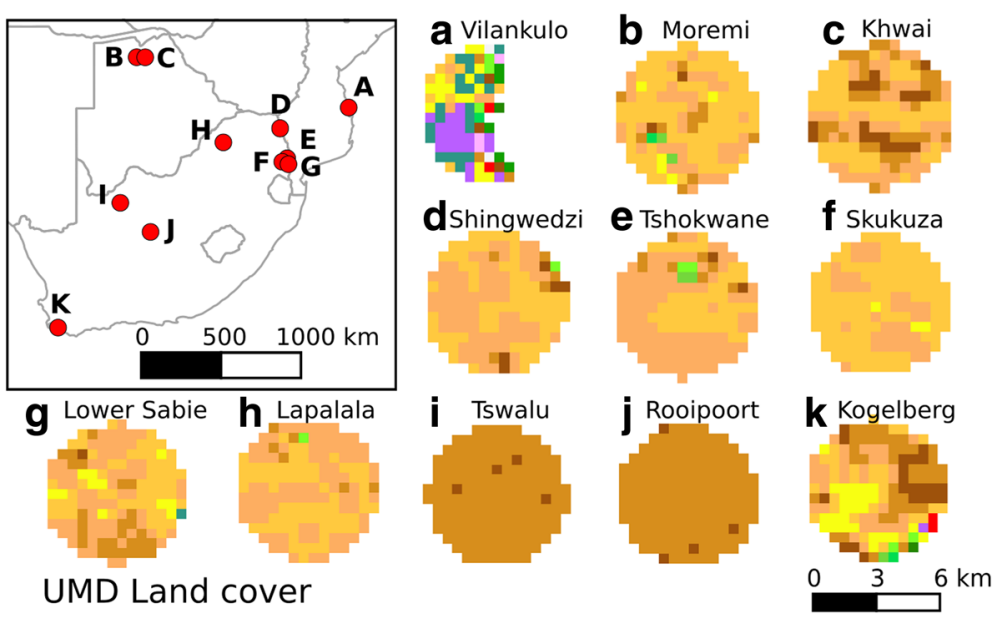

Evergreen Needleleaf forest

Evergreen Broadleaf forest

Woody Savannas

Deciduous Needleleaf forest

Savannas

Deciduous Broadleaf forest

Mixed forest

Closed shrublands

Open shrublands

$\square$ Grassland

Permanent wetlands

Croplands

Urban and built-up

Cropland/Natural vegetation mosaic

Fig. 1 Map of collection sites and their land cover type within a $3 \mathrm{~km}$ radius area (a-k). The latest (2013) University of Maryland Land (UMD) cover type data was used. Snow/lce and Barren land cover type are omitted from UMD legend as our study localities do not include any of those categories. Capital letters superimposed on the map insert correspond to equivalent small letter landcover charts

Supplementary mosquito collections were performed on an ad-hoc basis using larval dipping for larvae and pupae, (method described in [71]), and sweep netting and pyrethrum knock down catches for adults. After capture the larvae and pupae were reared individually to adults in single tubes provided with fish flakes (Tetra-Min ${ }^{\mathrm{Tm}}$ - Tetra
Holdings, VA, USA) as a food source. Pyrethrum knock down catches were performed in homes in Mozambique.

\section{Species identification methods}

Morphological species identification was carried out using keys and descriptions [59, 60, 72, 73]. In cases of

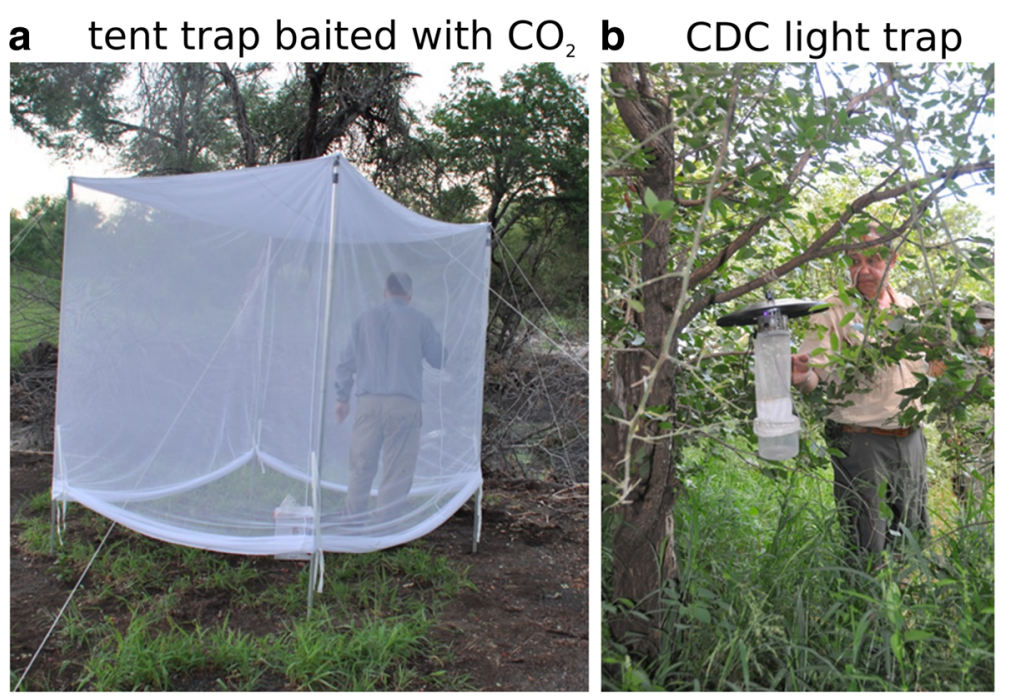

Fig. 2 Traps used for this study. a Mosquito net trap baited with polystyrene box containing dry ice placed on the ground in centre of trap. $\mathbf{b}$ Center for Disease Control (CDC) light trap with white light baited with dry ice 
doubt in the morphological identifications, pinned specimens were compared with specimens in the reference collections of the South African National Institute for Communicable Diseases. For members of the Anopheles gambiae complex and Anopheles funestus group, laboratory PCR identifications were done on individuallytubed specimens preserved in tubes containing silica gel (funestus group) or $80 \%$ ethanol (gambiae complex) following protocols in [74-76], respectively. Anopheles funestus group members from Moremi and Khwai were not identified to group member because the DNA of these specimens was too degraded for preservation by the time we got back to the base camp.

In southern Africa, Culex quinquefasciatus and Culex pipiens do not hybridize and are easily distinguishable as adults [77]. Some adult female species cannot be reliably distinguished and in these instances they were identified to the two possible species they could be.

\section{Data analysis}

Net and light trap mosquito species counts were averaged across all the nights of mosquitoes captured at each location. Species composition comparisons between net and light traps were done using Wilcoxon rank sum test $(P>0.5)$ using the R statistical package [78].

Pie charts depicting the percent proportions of catches represented by each of the major species (CDC light and net trap counts combined) in each location were created in Microsoft Excel (Version 2010) based on the raw capture data provided in Additional file 1: Table S1. CDC light traps were not performed in Vilankulo and Lower Sabie so the pie charts relevant to these locations represent only net trap data species compositions. All species that contributed relative percentage catches below $0.5 \%$ of the total catch were represented as "other spp." pertaining to their specific genera in the pie charts. Color coding for each species was kept consistent for all pie charts.

We selected two measures for depicting taxonomic richness and species diversity. To reflect taxon richness we developed a simple indicator that provides a 'one-glance catch-all' measure of the number of individuals caught in a trap, followed by the number of species and then genera in brackets. For example, if 300 mosquitoes representing 12 species and 5 genera were caught in a particular trap then this catch is summarized as '300 (12) [5]'. For ease of reference in the discussion below, we refer to the simple numeric 'catch-all' measure as the 'Community Composition Measure' (CCM). As a measure of species diversity we used the Shannon's index $(\mathrm{H})$ [79], which takes into account not only the number of taxa (species in our case) but also the relative abundance in which the different species are represented in the catch. For example, a trap catch having 100 individuals made up of 2 species and each of the 2 species represented by 50 individuals will have a higher score $(\mathrm{H}=0.693)$ than a trap catch of 100 mosquitoes made up of 2 species but of those, one species is represented by 90 individuals $(\mathrm{H}=0.325)$. This index is commonly used in ecology to provide information about community composition reflecting not only the unique number of species but also its abundance [80].

QGIS version 2.18.4 was used for generating the land cover maps based on the University of Maryland (UMD) Year 2013 Land Cover Classifications. The 2013 UMD Land cover data was extracted from MCD12Q1 MODIS Land Cover Type product available from Land Processes Distributed Active Archive Center (https://lpdaac.usgs. gov/dataset_discovery/modis/modis_products_table/ mcd12q1) using the HDF-EOS to GeoTIFF Conversion Tool (HEG) version 2.14 .

Morisita-Horn index [81] was calculated as measure of species composition similarity following the recommendation by Wolda [82]. Morisita-Horn index of 0 means no similarity and its value close to 1 means high similarity in species composition. A dendrogram based on the Morista-Horn index similarity matrix was generated using Scipy python library (https://www.scipy.org/).

\section{Results}

A total of 7882 mosquitoes were collected. Sixty-six species from 8 genera were collected in either or both the net and CDC traps and an additional 8 species, thus bringing the overall total to 74 , were collected as larvae and other supplementary collections. Supplementary collections were not included in the diversity indices calculations. Additional file 1: Table S1 provides a full list of species collected, and includes a summary of geographical localities each species was found in, the total number and percentage of total catch each species comprised, the known pathogens vectored by each of the species, and reference to the publication confirming their role as a vector. Pie charts representing species composition percentages for combined net and CDC light traps are provided in Fig. 3.

In Kogelberg, a specimen keyed out as Uranotaenia hopkinsi, a species that according to Jupp [60] occurs in Mozambique and not in South Africa. However, morphological features such as, (i) broad band of bluish scales along eye margins, (ii) pale scales at base of wing vein $R$, and (iii) broad patch of bluish white scales at wing root, were noted in the mosquito from Kogelberg, which are characters that differ slightly from that described for Ur. hopkinsi [69].

Culex quinquefasciatus, represented by 1708 individuals, was the most abundantly captured mosquito, but $>99 \%$ of these were collected in one locality (Vilankulo, Mozambique, see Shannon's H in Fig. 4). Mansonia uniformis, with 1505 individuals captured from 8 different trapping locations, was more equitably abundant over the 


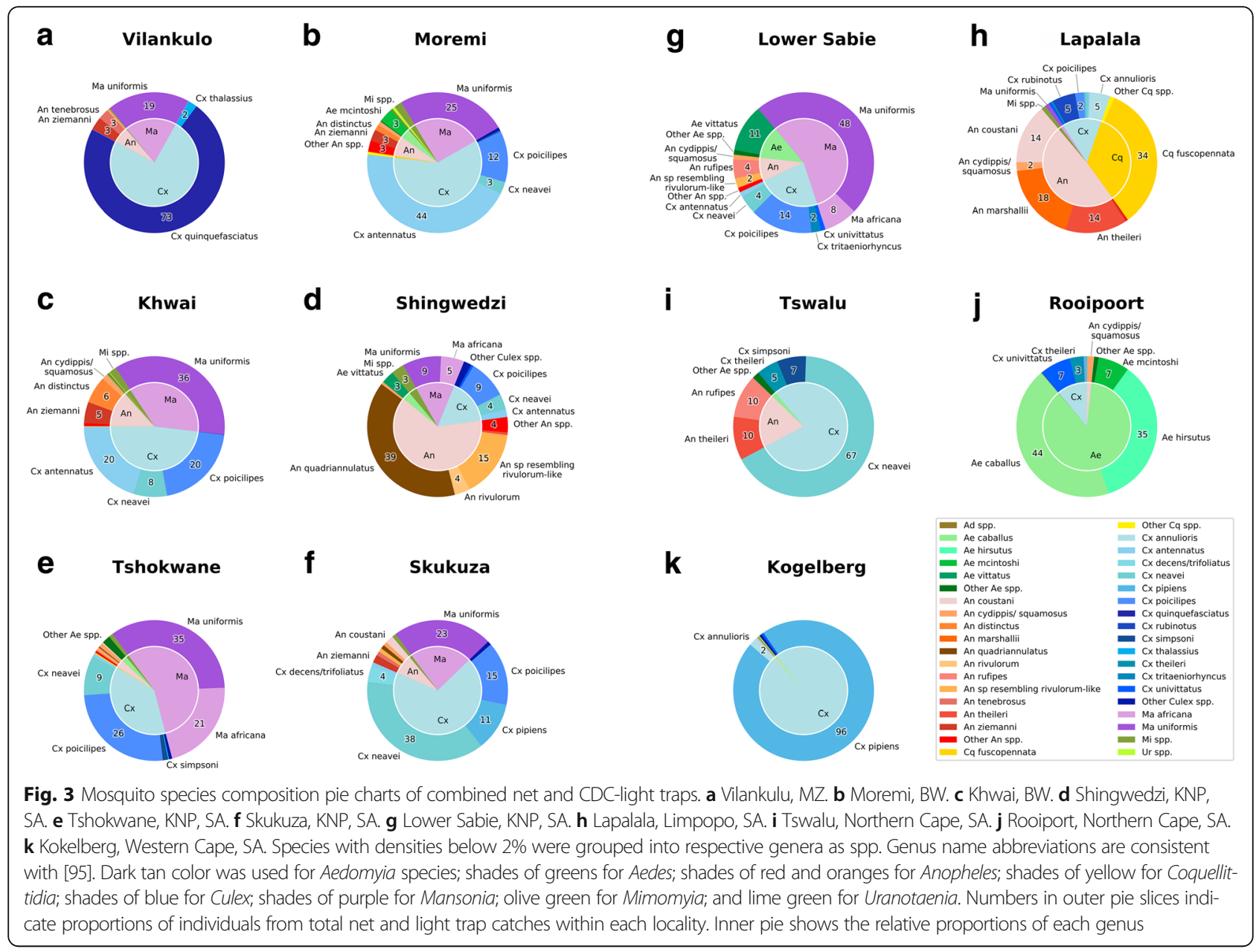

southern African region, followed by Culex antennatus $(n=876), C x$. pipiens $(n=689)$ and Cx. poicilipes $(n=592)$. Fourteen species were represented by only one specimen having been caught. The species found in the largest number of localities were Anopheles squamosus, $C x$. antennatus, $C x$. neavei, $C x$. poicilipes, $C x$. univittatus and Mansonia uniformis. Of all genera, Culex was the genus represented by the most species $(n=27)$.

Malaria vector species were collected mainly in Vilankulo, and a few in Moremi, Khwai and the Kruger National Park.

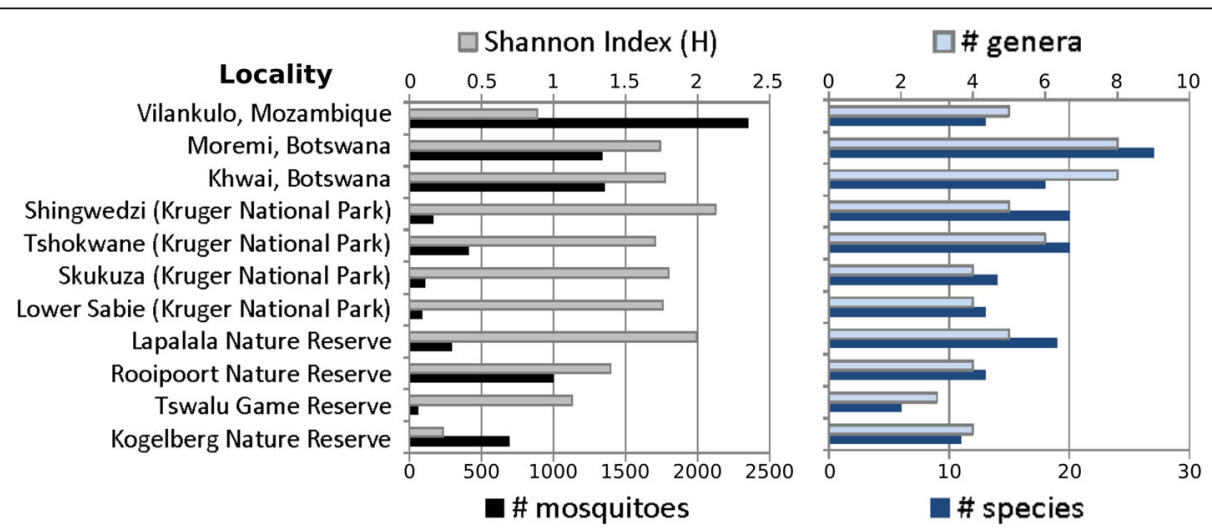

Fig. 4 Species diversity measures for each location. Shannon's index (top X axis) are represented in gray bars, the total number of mosquito specimens collected (bottom $X$ axis) in black, the number of unique genera (top axis) in light blue and the total number of unique species (bottom $X$ axis) are in dark blue 
Table 2 Species collected in either net or CDC light traps. Species collected in multiple locations are highlighted in bold

\begin{tabular}{ll}
\hline Species only found in net traps & Species only found in light traps \\
\hline Ae. juppi $(n=3)$ & Ae. aegypti $(n=1)$ \\
Ae. ochraceus $(n=8)$ & Ae. fowleri $(n=1)$ \\
An. longipalpis $(n=1)$ & Ae. ledger $(n=1)$ \\
An. parensis $(n=3 ; 3$ & Ae. mixtus/microstictus $(n=1)$
\end{tabular}

locations: Shingwedzi

Vilankulo and Lower Sabie)

Coq. maculipennis $(n=3)$

Cx. aurantapex $(n=2 ; 2$ locations: Moremi and Tshokwane)

Cx. decens/trifoliatus $(n=4)$

\section{Cx. quinquefasciatus}

$(n=1708 ; 2$ locations:

Vilankulo and Rooipoort)

CX. salisburiensis $(n=1)$

Ae. simpsoni $(n=1)$

Ae. subdentatus $(n=1) /$ Aedeomyia africana $(n=1)$; Ae. furfurea ( $n=10 ; 3$ locations: Moremi, Khwai and Rooipoort)

Cx. chorleyi $(n=2)$

Cx. duttoni $(n=1)$

CX. nebulosus $(n=1)$
CX. pulchrithorax $(n=1)$

Mi. splendens ( $n=25 ; 3$ locations: Moremi, Khwai and Shingwedzi)

Ur. hopkinsi $(n=1)$

Ur. mashonaensis $(n=1)$

However, a significant proportion of mosquitoes that vector arboviruses were collected at all locations in combined net and CDC light traps (Table 1: \% vectors and $\mathrm{CCM}_{\mathrm{av}}$ ). Their numbers of individuals comprise more than half of the total mosquito catches, except in Shingwedzi (KNP).

A significant difference in species captured between net and CDC light traps was found in all locations (Table 1, in bold print), except for in Tswalu, (Wilcoxonrank sum test, $\mathrm{V}=36-630, P$-value $<0.0008)$. There was no significant advantage of CDC light traps over net traps in capturing higher numbers of different species (Wilcoxon-rank sum test $P$-value $>0.5$ ). There were 9 species that were captured only in net traps and 14 species only in the CDC light traps (Table 2).

The Community Composition Measure (CCM) of mosquito numbers (Table 1, Fig. 4), indicated the highest species richness (31 species in 6 genera) along the Sabie River and Tshokwane Picnic Site in the southern KNP. CCM indicated the lowest species richness at Tswalu Game Reserve in the arid Kalahari (6 species in 3 genera). The Moremi Game Reserve and Khwai Conservancy in the Okavango Delta of Botswana had fewer species than in the southern KNP but had more genera represented ( 29 species in 8 genera), but catch sizes were also much larger in Okavango.

With Shannon's index greater than 1.7, Kruger National Park (KNP) and Botswana localities had greater mosquito diversities than other localities (Table 1, Fig. 4). The number of species captured in Vilankulo and Kogelberg was comparable to Kruger National Park sites but Shannon's diversity index was lower than 1, indicating less evenness of species composition (Fig. 4). The number of species collected in Tswalu Game Reserve was lowest, but its diversity index (Shannon's H) was higher than Vilankulo and Kogelberg, indicating the more evenness in species composition (Fig. 4). The species diversity represented in Shannon's index $(\mathrm{H})$ correlated with latitude $\left(R^{2}=0.4415\right.$, linear model $P$-value $=0.0257)$. Correlation between $\mathrm{H}$ and historic precipitation (WorldClim version 2.0) was not significant (linear model $P$-value $>0.05$ ).

Similarity in species composition between localities, measured as Morisita-Horn Index [81], show that southern Kruger National Park (KNP; Lower Sabie, Skukuza and Tshokwane) and Botswana (Moremi and Khwai)
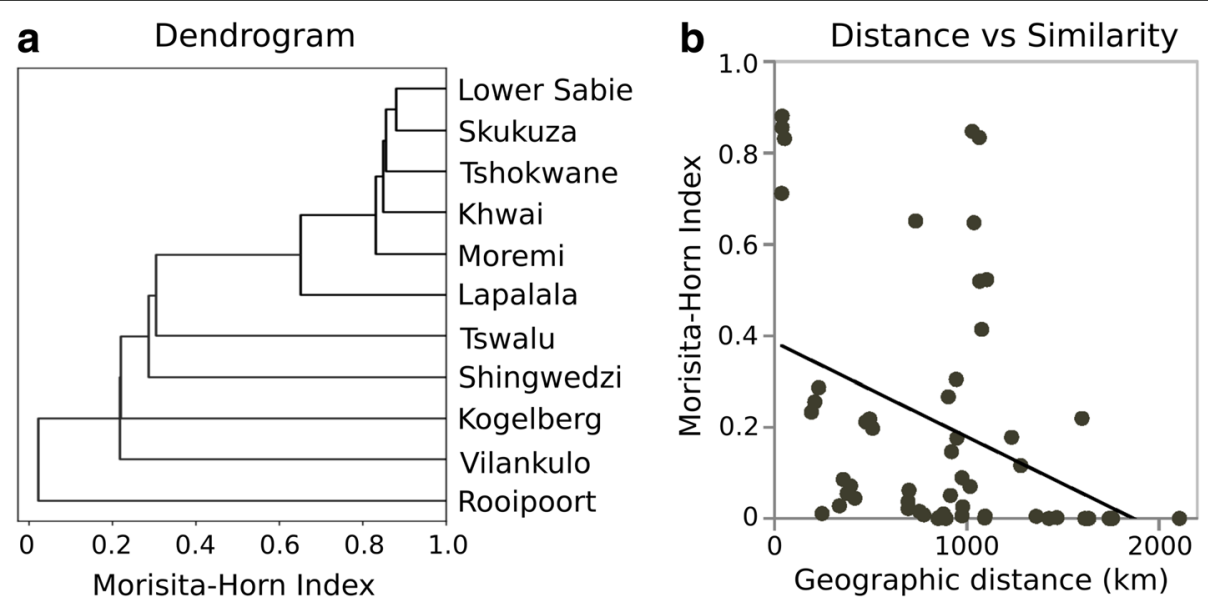

Fig. 5 Species composition similarity. a Dendrogram based on the pair-wise Morisita-Horn Index, a measure of species composition similarity between any two localities. b Relationship between species composition similarity measured as Morisita-Horn Index and geographical distance (Linear model slope $=-0.0002, R^{2}=0.1399, P$-value $=0.005$ ) 
were similar (Morisita-Horn Index $>0.8$ ) as shown in Fig. 5a. Generally, the species composition similarity decreased as geographical distance between two localities increased (Fig. 5b). Botswana and KNP were exceptions to this rule as they are almost $1000 \mathrm{~km}$ apart but yet had similar species compositions. Hence, other factors such as land cover types and availability of blood source may be affecting species composition. However, due to the limited number of sites we surveyed, we did not have enough power to detect any significant relationship between land cover types and species diversity and/or composition.

\section{Discussion}

In a country or region where relatively little is known about mosquito populations, or presence of arboviruses, understanding the potential for arbovirus transmission is dependent on answering the following key questions "What species occur here?" and "How abundant are they and how do they vary in time and space?". Given the potential for rapid spread of arboviruses at global scale $[83,84]$, and their alarming public health impacts and little capacity to prevent this [85], answers to these key questions are becoming increasingly important. These questions are even more important on the African continent where many of the current crop of emerging and re-emerging viruses have originated. Africa also hosts many relatively quiescent viruses that remain confined to sylvatic cycles.

Trapping was not done within five $\mathrm{km}$ of the rest camps within the wildlife reserves, to avoid collections of mosquitoes associated with human habitats. However, it should be noted that at the rest camps in Tswalu and Rooipoort nature reserves, Ae. aegypti and Culex quinquefasciatus were profound nuisances. Both of these mosquitoes are arbovirus vectors and potentially pose a risk of arbovirus transmission to guests if the viruses were inadvertently introduced.

Our CCM metric provides an intuitive sense of mosquito population attributes, that enables one to instantly get a 'sense' of species diversity represented in a given area (Table 1). Our trapping methods were proven to be effective in capturing potential vector species as indicated in Table 1. All locations have more than three species and two genera that are known to be arbovirus vectors (Table 1). The high numbers of one vector species, namely $C x$. pipiens and $C x$. quinquefasciatus (> $90 \%)$ in Kogelberg and Vilankulo, respectively, is concerning in terms of transmission potential.

Our survey also demonstrated the high degree of consistency using a combination of net traps and light traps to quickly sample mosquito species richness in a particular locality. For instance, southern Kruger National Park sites (Skukuza, Tshokwane and Lower
Sabie) all had $\mathrm{H}$ around 1.7 (Table 1, Figs. 3 and 4) and their species compositions were very similar (MorisitaHorn Index $>0.8$; Fig. 5). We collected most of the species $(89.2 \%$, of 74 species) using these two trap types and additional sampling of mosquitoes by way of collecting larvae in tree-holes, rock-pools and various other habitats, and sweep-netting through tall and dense grass along riverbanks, and conducting pyrethrum knockdown sprays in Vilankulo yielded relatively fewer species. Because of the significant differences in species captured between the net and CDC-light traps at almost all locations, we recommend using both trap types for species diversity and for outdoor biting arbovirus and malaria vector surveillance.

Despite the relative efficiency of our sampling design to survey the diversity of carbon-dioxide-attracted mosquitoes within the space of three to four days at a particular locality, clear shortfalls have also become apparent. Two years after this survey, we collected mosquitoes at Shingwedzi (KNP) in March 2017 for ten days following two months of sustained good and regular rainfall, which created excellent breeding conditions for many mosquito species. This survey yielded several additional species not found during the 2015 survey. These included Aedes sudanensis, Anopheles arabiensis and Culex tigripes. The reverse was also true, that despite highly favourable conditions, some species were not collected during March 2017 but were caught under very average conditions of March 2015. Furthermore, copious numbers of An. arabiensis were collected by Cornel, Lee and Braack, in Lapalala in February 2017, a species that had not been collected in this region for many years. There were also multiple reported cases of malaria in this region which had also been malaria free for many years previously, indicating that species distributions contract and expand periodically. This emphasises the obvious though, that a single visit even during a 'good season' will not yield an exhaustive catch of all species and that repeat visits in different seasons over several years are necessary to achieve a 'complete' picture of mosquito diversity in a region or to monitor trends in mosquito community composition.

Despite most of our sampling localities being situated in hot, summer rainfall areas, in the bushveld or savanna habitats, with abundant surface water available and similar mix of plentiful wildlife (blood meal sources) and despite the known presence of both members of the Anopheles gambiae complex being present in the Okavango Delta (Moremi, Khwai), and KNP, only Anopheles arabiensis was captured in the Okavango traps and only Anopheles quadriannulatus in the traps at KNP. However, larvae collected in one elephant footprint pool at Lower Sabie in southern KNP and reared to adulthood yielded a mix of Anopheles arabiensis and A. quadriannulatus, suggesting 
that the absence of one or the other species in the traps was simply an artefact of chance. The ecological determinants underpinning local dominance and abundance of these two partially sympatric species are poorly understood, with one species predominating in one region of sympatry, such as Anopheles arabiensis apparently more common than in the Okavango Delta than An quadriannulatus [86], the reverse apparently applying in the Mpumalanga Province of South Africa [87, 88], all or which likely plays a role in the presence of these species in trap catches.

Although our survey is limited in geographical and trap coverage, we found high species richness and diversity in extensive wildlife conservation areas. These areas retain historic ecological integrity and habitat diversity and are moderately or well supplied with good quality surface water for breeding substrate and have readily available sources of blood meals in the form of birds and mammals. These conditions exist in the Okavango Delta, Kruger National Park, and Lapalala Game Reserve, which all show Shannon's indices above 1.7, but lower levels of diversity are present at localities where essential elements of favourable habitat are lacking, such as in the Kogelberg which had few medium to large birds and mammals, and Rooipoort and Tswalu Nature Reserve, which have adequate birds and mammals but very little surface water appropriate for mosquito breeding.

Subsets of the data can be usefully compared with findings of other studies. For example, Ngomane et al. [89] found that in a sample of 319 Anopheles funestus group mosquitoes collected from eight sites in Mpumalanga Province of South Africa between 2002-2005, 7. 8\% were Anopheles funestus (sensu stricto), 60.2\% An. rivulorum (presumably includes An. rivulorum-like), 10. 7\% An. vaneedeni, 10.9\% An. parensis and 10.3\% An. leesoni. Our collective sample of 63 Anopheles funestus group captured over a two-week visit (includes a few individuals collected from traps not reported on here) at five collection areas in Kruger National Park comprised $77.7 \%$ specimens resembling An. rivulorum-like, $17.5 \%$ An. rivulorum, $3.2 \% \mathrm{An}$. parensis and $1.6 \% \mathrm{An}$. leesoni. These differences in species assemblage across geographically-adjoining areas are likely due to different sampling methodologies, Ngomane et al. [89] obtaining most of their specimens from night-time human landing catches and day-time catches of mosquitoes resting in natural shelters, compared to our net trap and light trap techniques. These differences also emphasize the need to standardize trapping techniques to allow for valid comparisons.

Steyn et al. [90] spent 15 days sampling mosquitoes at multiple sites along the Limpopo River valley, covering some 300 miles from Vaalwater (very close to Lapalala Game Reserve) eastwards to the northern Kruger National
Park at Pafuri (not far from Shingwedzi). Similar to our sampling surveys at Lapalala and Shingwedzi, their survey was also in March in late wet-season. Their survey yielded 538 mosquitoes comprising 21 species in three genera. Their catches are of the same general scale as ours, where we record 20 species (5 genera) at Shingwedzi and 19 (5 genera) at Lapalala in much shorter collection periods. Steyn et al. [90] based their publication mostly on larval collections (409 larvae) from tree-holes, pools at quarries and borrow-pits, rock pools and even large snail shells, supplemented with adult catches (129). Importantly however, despite the similarity in species richness, nearly $50 \%$ of the species they caught or reared were different to those in our collections, with a predominance of Aedes species as can be expected from the types of breeding sites they sampled. Once again, the need to standardize collection techniques is emphasized. Long term monitoring of mosquito populations and comparisons between different sites are reliant on quick efficient trapping techniques directed at sampling important species, whilst ecological studies aimed at understanding species richness will require a wide a range of collection methods.

The Shingwedzi River and Sabie River collection areas roughly bisect the northern and southern regions of the Kruger National Park in South Africa. The habitat along these rivers is fairly representative of these two regions, especially as it relates to mosquito breeding site types. In March 2015, we collected 20 species (5 genera) in the north and 31 species (6 genera) in the south of KNP. In April 1953, Schultz et al. [91] surveyed culicine mosquitoes by way of larval collections throughout the KNP, and collected a total of 907 mosquitoes (799 larvae, 108 adults) made up of 25 species in four genera; three species were Anopheles, one Orthopodomyia, 12 Aedes and nine Culex. Schultz et al. [91] collected 12 species and one genus (Orthopodomyia) over 18 days that we did not collect in our stay in eight days. Conversely, we collected 15 species and three genera (Coquellittidia, Mansonia and Mimomyia) that they did not collect. Clearly each collection method has its own limitations and there is a need to clearly identify the purpose of the survey and to design appropriate sampling strategies to optimize appropriately targeted outcomes, especially if time and manpower are limited. Our combination of net traps and light traps proved efficient in yielding a good range of species and genera in very limited time, and were good at collecting a wide range of Culex and Anopheles species not well represented in the Schultz et al. [91] and Steyn et al. [90] collections, but were poor at trapping Aedes in comparison with the larval collections in the Steyn et al. [90] and Schultz et al. [91] collections.

To give some sense of what kind of species richness can be expected after very intensive and continuous sampling; van der Linde et al. [92] placed four light traps at weekly intervals for three years in a rural area near Bloemfontein 
in the central region of South Africa. They collected 143,438 mosquitoes representing 25 species in four genera, of which $85 \%$ were of the three species Aedes juppi, Aedes durbanensis and Culex theileri. Our Rooipoort site is within a couple of hundred kilometres from Bloemfontein, and we collected 1000 mosquitoes representing 13 species in 4 genera during five days of sampling using net traps and light traps. This again suggests that even relatively short sampling periods of three to five days using $\mathrm{CO}_{2}$ baited net traps and light traps can be effective in providing broad insight to species composition and abundance if done at the appropriate seasonal time.

\section{Conclusions}

For disease epidemiological or surveillance aimed at collecting mosquitoes of as broad a range of species as quickly as possible, our findings suggest that a combination of night-operated $\mathrm{CO}_{2}$ baited net traps and light traps provides good representation of mosquito diversity and abundance in an area even during relatively short sampling visits lasting 3-5 nights. Anopheles, Culex, Mansonia, Coquellittidia and Mimomyia are well represented in our collections, but Aedes appeared to be underrepresented. This may be because many Aedes are predominantly day-biting and, at least in some cases, also have shorter periods of seasonal abundance. For Aedes collections it is therefore probably better to do larval collections from container habitats, supplemented with dayoperated odour-baited BG traps or similar devices [93]. We also find a simple Community Composition Measure (CCM) which combines numbers of mosquitoes captured, number of species, and number of genera, a far more useful indicator of mosquito community status and structure at a particular sampling site than the Shannon's index, although the two measures do complement each other and together provide a more informed assessment. Limited time and resources constrained our ability to develop a finer-grained understanding of mosquito communities across South Africa, yet the selected broad coverage of the sites represented in this study does provide good initial insight as to where high diversity and numbers are likely to be found, such as in the extensive untransformed conservation areas located in warm climates and having a combination of diverse mammals and birds as blood meal source and good stands of surface water of different types; arid environments and areas poor in birds and animals appear to support lower species richness. This may seem intuitively obvious, but is useful confirmation.

\section{Additional file}

Additional file 1: Table S1. Mosquito species capture data and disease vector status for each of the mosquito species captured. (XLSX $31 \mathrm{~kb}$ )

\section{Abbreviations}

BAGV: Bagaza virus; BANV: Banzi virus; BATV: Batai virus; BBKV: Babanki virus; BUNV: Bunyamwera virus; BWAV: Bwambwa virus; CCM: Community Composition Measure; CDC: Centers for Disease Control and Prevention; CHIKV: Chikungunya virus; CYV: Chaoyang virus; DENV1-4: Dengue virus serotypes 1 to 4; GERV: Germiston virus; H: Shannon Index; KNP: Kruger National Park; MIDV: Middelburg virus; NDUV: Ndumu virus; NRIV: Ngari virus; ONNV: O'Nyong-Nyong virus; PGAV: Pongola virus; QBV: Quang Binh virus; RVFV: Rift Valley fever virus; SFV: Semliki Forest virus; SHUV: Shuni virus; SINV: Sindbis virus; SPOV: Spondweni virus; UGSV: Uganda S virus; USUV: Usutu virus; WESV: Wesselsbron virus; WITV: Witwatersrand virus; WNV: West Nile virus; YFV: Yellow fever virus; ZIKV: Zika virus

\section{Acknowledgements}

AC and LB thank the Carnegie Foundation for an African Diaspora Fellowship grant. LB thanks SASOL Petroleum for enabling the Vilankulo collections which formed part of Malaria Control Programme Support activities. We gratefully acknowledge the UP ISMC \& MRC Collaborating Centre for Malaria Research of the University of Pretoria for institutional support especially during the field work phase leading up to this publication. We thank Dr Danny Govender and SANParks staff for generous logistical assistance as well as Mr Anton Walker and staff of the Lapalala Wilderness Reserve for permission to collect and assistance rendered. The following agencies provided permits allowing mosquito collections in their areas of jurisdiction or for cross-border importation of dead mosquitoes, for which we extend our thanks: Botswana Department of Wildlife and National Parks, Cape Nature, E Oppenheimer \& Son, SANParks, South African Department of Agriculture, Forestry \& Fisheries.

\section{Funding}

AC was a recipient of the Carnegie African Diaspora Fellowship grant funding program. PA was funded through a University of Pretoria visiting Professorship and Todd Johnson is a recipient of a studentship award from the Centers for Disease Control and Prevention. "Fundação para a Ciência e a Tecnologia" for funds to GHTM - UID/Multi/04413/2013.

\section{Availability of data and materials}

The data supporting the conclusions of this article are included within the article and Additional file 1: Table S1.

\section{Authors' contributions}

AC and LB did the fieldwork, assisted at times by PA. AC did the mosquito identifications, assisted at times by JM, YL and PA. LB, PA and YL conducted data analysis. $L B$ and $A C$ conceptualized and wrote the manuscript drafts, with subsequent additions and editorial comments by all other authors. LB conceptualized and developed the community composition measure. All authors read and approved the final manuscript.

Ethics approval and consent to participate

Not applicable.

Consent for publication

Not applicable.

\section{Competing interests}

The authors declare that they have no competing interests.

\section{Publisher's Note}

Springer Nature remains neutral with regard to jurisdictional claims in published maps and institutional affiliations.

\section{Author details}

'Department of Entomology \& Nematology, University of California, Davis, USA. ${ }^{2}$ UP Institute for Sustainable Malaria Control \& MRC Collaborating Centre for Malaria Research, Faculty of Health Sciences, University of Pretoria, Pretoria, South Africa. ${ }^{3} \mathrm{Global}$ Health and Tropical Medicine, GHTM, Institute for Hygiene and Tropical Medicine, IHMT, Universidade Nova de Lisboa, UNL, Lisbon, Portugal. ${ }^{4}$ Centre for Viral Zoonoses, Faculty of Health Sciences, University of Pretoria, Pretoria, South Africa. 


\section{Received: 7 November 2017 Accepted: 28 March 2018} Published online: 01 June 2018

\section{References}

1. Coetzee M, Kruger P, Hunt RH, Durrheim DN, Urbach J, Hansford CF. Malaria in South Africa: 110 years of learning to control the disease. S Afr Med J. 2013;103:770-8

2. De Meillon B. The control of malaria in South Africa by measures directed against adult mosquitoes in habitations. Q BHealth Organ. 1936;5:134-7.

3. Hill E, Haydon LG. The epidemic of malaria fever in Natal. J Hyg. 1905;5:467-84.

4. Mabaso ML, Sharp B, Lengeler C. Historical review of malarial control in southern African with emphasis on the use of indoor residual housespraying. Tropical Med Int Health. 2004;9:846-56.

5. Swellengrebel NH, de Meillon B. Malaria investigations in some parts of Transvaal and Zululand. Johannesburg: South African Institute for Medical Research; 1931.

6. Brooke BD, Robertson L, Kaiser ML, Raswiswi E, Munhenga G, Venter N, et al. Insecticide resistance in the malaria vector Anopheles arabiensis in Mamfene, KwaZulu-Natal. S Afr J Sci. 2015;111:1-3.

7. Choi KS, Koekemoer LL, Coetzee M. Population genetic structure of the major malaria vector Anopheles funestus s.s. and allied species in southern Africa. Parasit Vectors. 2012:5:283.

8. Coleman M, Casimiro S, Hemingway J, Sharp B. Operational impact of DDT reintroduction for malaria control on Anopheles arabiensis in Mozambique. J Med Entomol. 2008:45:885-90

9. Kloke RG, Nhamahanga E, Hunt RH, Coetzee M. Vectorial status and insecticide resistance of Anopheles funestus from a sugar estate in southern Mozambique. Parasit Vectors. 2011:4:16.

10. Masendu HT, Hunt RH, Govere J, Brooke BD, Awolola TS, Coetzee M. The sympatric occurrence of two molecular forms of the malaria vector Anopheles gambiae Giles sensu stricto in Kanyemba, in the Zambezi Valley, Zimbabwe. Trans R Soc Trop Med Hyg. 2004;98:393-6.

11. Mouatcho JC, Hargreaves K, Koekemoer LL, Brooke BD, Oliver SV, Hunt RH, Coetzee M. Indoor collections of the Anopheles funestus group (Diptera: Culicidae) in sprayed houses in northern KwaZulu-Natal, South Africa. Malar J. 2007;6:30

12. Norris LC, Norris DE. Phylogeny of anopheline (Diptera: Culicidae) species in southern Africa, based on nuclear and mitochondrial genes. J Vector Ecol. 2015:40:16-27.

13. Ntomwa BN, Usuku P, Govere JN, Manga L, Koekemoer LL, Hunt RH, Coetzee M. Distribution of members of the Anopheles gambiae Giles s.l. complex in Namibia and susceptibility to insecticides used for malaria control. Afr Entomol. 2006;14:404-6.

14. Anderson D. Ecological studies on Sindbis and West Nile viruses in South Africa. III. Host preferences of mosquitoes as determined by the precipitin test. S Afr J Med Sci. 1967;32:34-9.

15. Gargan TP 2nd, Jupp PG, Novak RJ. Panveld oviposition sites of floodwate Aedes mosquitoes and attempts to detect transovarial transmission of Rift Valley fever virus in South Africa. Med Vet Entomol. 1988;2:231-6.

16. Gear J, De Meillon B, Le Roux AF, Kofsky R, Innes RR, Steyn JJ, et al. Rift valley fever in South Africa; a study of the 1953 outbreak in the Orange Free State, with special reference to the vectors and possible reservoir hosts. S Afr Med J. 1955;29:514-8.

17. Jupp PG. Chapter 6. Vectors: Mosquitoes. In: Coetzer JAW, Tustin RC, editors. Infectious diseases of livestock. 2nd ed. Oxford: Oxford University Press; 2004. p. 137-52

18. Jupp PG, McIntosh BM. Ecological studies on Sindbis and West Nile viruses in South Africa. II. Mosquito bionomics. S Afr J Med Sci. 1967;32:15-33.

19. Jupp PG, McIntosh BM, Thompson DL. Isolation of Rift Valley fever virus from Aedes (Neomelaniconion) circumluteolus and/or luteolateralis collected during an outbreak in cattle in the coastal region of Natal, South Africa. S Afr J Sci. 1983;79:377.

20. Jupp PG, McIntosh BM, Thompson DL. Mechanical transmission of Rift Valley fever virus by mosquitoes. S Afr J Sci. 1984:80:276.

21. Muspratt J. Research on South African Culicini (Diptera, Culicidae). III. - A check-list of the species and their distribution, with notes on taxonomy, bionomics and identification. J Entomol Soc South Afr. 1955;18:149-207.

22. Muspratt J. The Stegomyia mosquitoes of South Africa and some neighbouring territories. Including chapters on the mosquito-borne virus diseases of the Ethiopian zoo-geographical region of Africa. Mem Entomol Soc S Afr. 1956:4:1-138.
23. De Meillon B, Paterson HE, Muspratt J. Studies on arthropod-borne viruses of Tongaland. II. Notes on the more common mosquitoes. S Afr J Med Sci. 1957;22:47-53.

24. Kokernot RH, Smithburn KC, Weinbren MP, De Meillon B. Studies on arthropod-borne viruses of Tongaland. VI. Isolation of Pongola virus from Aedes (Banksinella) circumluteolus Theo. S Afr J Med Sci. 1957;22:81-92.

25. Kokernot RH, Smithburn KC, Muspratt J, Hodgson B. Studies on arthropodborne viruses of Tongaland. VIII. Spondweni virus, an agent previously unknown, isolated from Taeniorhynchus (Mansonioides) uniformis. S Afr J Med Sci. 1957;22:103-12

26. Kokernot RH, Heymann CS, Muspratt J, Wolstenholme B. Studies on arthropod-borne viruses of Tongaland. V. Isolation of Bunyamwera and Rift Valley Fever viruses from mosquitoes. S Afr J Med Sci. 1957:22:71-80.

27. Kokernot RH, De Meillon B, Paterson HE, Heymann CS, Smithburn KC. Middelburg virus; a hitherto unknown agent isolated from Aedes mosquitoes during an epizootic in sheep in the eastern Cape Province. S Afr J Med Sci. 1957:22:145-53.

28. Smithburn KC, Kokernot RH, Weinbren MP, De Meillon B. Studies on arthropod-borne viruses of Tongaland. IX. Isolation of Wesselsbron virus from a naturally infected human being and from Aedes (Banksinella) circumluteolus Theo. S Afr J Med Sci. 1957;22:113-20.

29. Worth CB, de Meillon B. Culicine mosquitoes (Diptera: Culicidae) recorded from the province of Mozambique (Portuquese East Africa) and their relationship to arthropod-borne viruses. An Inst Med Trop. 1960;17:231-56.

30. Jupp PG, McIntosh BM. A bionomic study of adult Aedes (Neomelaniconion) circumluteolus in northern Kwazulu, South Africa. J Am Mosq Control Assoc. 1987;3:131-6

31. Cornel AJ, Jupp PG, Blackburn NK. Environmental temperature on the vector competence of Culex univittatus (Diptera: Culicidae) for West Nile virus. J Med Entomol. 1993:30:449-56.

32. Jupp PG, Kemp A. Laboratory vector competence experiments with yellow fever virus and five South African mosquito species including Aedes aegypti. Trans R Soc Trop Med Hyg. 2002;96:493-8.

33. Kampango A, Abilio AP. The Asian tiger hunts in Maputo city - the first confirmed report of Aedes (Stegomyia) albopictus (Skuse, 1895) in Mozambique. Parasit Vectors. 2016:9:76.

34. Cornel AJ. Description of Aedes (Neomelaniconion) aurovenatus Worth (Diptera: Culicidae). Mosq Syst. 1991;23:54-65.

35. De Meillon B. Illustrated keys to the full-grown larvae and adults of South African anopheline mosquitoes. Publ S Afr Inst Med Res. 1931;4:275-375.

36. Koekemoer LL, Kamau L, Hunt RH, Coetzee M. A cocktail polymerase chain reaction assay to identify members of the Anopheles funestus (Diptera: Culicidae) group. Am J Trop Med Hyg. 2002;66:804-11.

37. McAbee RD, Christiansen JA, Cornel AJ. A detailed larval salivary gland polytene chromosome photomap for Culex quinquefasciatus (Diptera: Culicidae) from Johannesburg, South Africa. J Med Entomol. 2007:44:229-37.

38. Mclntosh BM. The aedine subgenus Neomelaniconion Newstead (Culicidae: Diptera) in southern Africa with descriptions of two new species. J Entomol Soc South Afr. 1971:34:319-33.

39. McIntosh BM. A taxonomic reassessment of Aedes (Ochlerotatus) caballus (Theobald) (Diptera: Culicidae) including a description of a new species of Ochlerotatus. J Entomol Soc South Afr. 1973;36:261-9.

40. Paterson HE. Direct evidence for the specific distinctness of forms $A, B$, and C of the Anopheles gambiae complex. Riv Malariol. 1964;43:191-6.

41. Braack LE, Coetzee M, Hunt RH, Biggs H, Cornel A, Gericke A. Biting pattern and host-seeking behavior of Anopheles arabiensis (Diptera: Culicidae) in northeastern South Africa. J Med Entomol. 1994:31:333-9.

42. Burke A, Dandalo L, Munhenga G, Dahan-Moss Y, Mbokazi F, Ngxongo S, et al. A new malaria vector mosquito in South Africa. Sci Rep. 2017;7:43779.

43. Cornel AJ, Jupp PG. Comparison of three methods for determining transmission rates in vector competence studies with Culex univittatus and West Nile and Sindbis viruses. J Am Mosq Control Assoc. 1989:5:70-2.

44. Cuamba N, Mendis C. The role of Anopheles merus in malaria transmission in an area of southern Mozambique. J Vector Borne Dis. 2009:46:157-9.

45. La Grange JJP, Coetzee M. A mosquito survey of Thomo Village, Northern Province, South Africa, with special reference to the bionomics of exophilic members of the Anopheles funestus group (Diptera: Culicidae). Afr Entomol. 1997;5:295-9.

46. Sharp BL, le Sueur D. Behavioral variation of Anopheles arabiensis (Diptera, Culicidae) populations in Natal, South-Africa. Bull Entomol Res. 1991;81:107-10 
47. Choi KS, Christian R, Nardini L, Wood OR, Agubuzo E, Muleba M, et al. Insecticide resistance and role in malaria transmission of Anopheles funestus populations from Zambia and Zimbabwe. Parasit Vectors. 2014;7:464.

48. Glunt KD, Abilio AP, Bassat Q, Bulo H, Gilbert AE, Huijben S, et al. Longlasting insecticidal nets no longer effectively kill the highly resistant Anopheles funestus of southern Mozambique. Malar J. 2015;14:298.

49. Hargreaves K, Hunt RH, Brooke BD, Mthembu J, Weeto MM, Awolola TS, Coetzee M. Anopheles arabiensis and An. quadriannulatus resistance to DDT in South Africa. Med Vet Entomol. 2003;17:417-22.

50. Mnzava AEP, Sharp BL, Cuamba N, Barreto A. Malaria vector studies in Maputo, Mozambique - implications for control. S Afr Med J. 1997:87:1611-4.

51. Mouatcho JC, Munhenga G, Hargreaves K, Brooke BD, Coetzee M, Koekemoer LL. Pyrethroid resistance in a major African malaria vector Anopheles arabiensis from Mamfene, northern KwaZulu-Natal, South Africa. S Afr J Sci. 2009;105:127-331.

52. Munhenga G, Masendu HT, Brooke BD, Hunt RH, Koekemoer LK. Pyrethroid resistance in the major malaria vector Anopheles arabiensis from Gwave, a malaria-endemic area in Zimbabwe. Malar J. 2008;7:247.

53. Govere J, Durrheim DN, Baker L, Hunt R, Coetzee M. Efficacy of three insect repellents against the malaria vector Anopheles arabiensis. Med Vet Entomol. 2000;14:441-4.

54. Davies C, Coetzee M, Lyons CL. Characteristics of larval breeding sites and insecticide resistance in the Anopheles gambiae complex in Mpumalanga, South Africa. Afr Entomol. 2016;24:421-31.

55. Koekemoer LL, Waniwa K, Brooke BD, Nkosi G, Mabuza A, Coetzee M. Larval salinity tolerance of two members of the Anopheles funestus group. Med Vet Entomol. 2014;28:187-92.

56. Le Sueur D, Sharp B. The breeding requirements of three members of the Anopheles gambiae Giles complex (Diptera: Culicidae) in the endemic malaria area of Natal, South Africa. Bull Entomol Res. 1988:78:549-60.

57. Mbokazi MF. Ecology of breeding sites and insecticide resistance of the potential malaria vectors in Mpumalanga Province, South Africa. Johannesburg: University of Witwatersrand; 2015.

58. Gillies M, De Meillon B. The Anophelinae of Africa south of Sahara. 2nd ed Johannesburg: The South African Institute for Medical Research; 1968.

59. Gillies MT, Coetzee M. A supplement to the Anophelinae of Africa south of the Sahara. Johannesburg: The South African Institute for Medical Research; 1987.

60. Jupp PG. Mosquitoes of southern Africa: Culicinae and Toxorhynchitinae. Hartebeespoort: Ekogilde Publishers; 1996.

61. Charrel RN, de Lamballerie X, Raoult D. Chikungunya outbreaks - the globalization of vectorborne diseases. N Engl J Med. 2007;356:769-71.

62. Enserink M. Infectious diseases. Chikungunya: no longer a third world disease. Science. 2007:318:1860-1.

63. Gubler DJ. Epidemic dengue/dengue hemorrhagic fever as a public health, social and economic problem in the 21 st century. Trends Microbiol. 2002;10:100-3.

64. Higgs S. Chikungunya virus: a major emerging threat. Vector Borne Zoonotic Dis. 2014;14:535-6.

65. Semenza JC, Sudre B, Miniota J, Rossi M, Hu W, Kossowsky D, et al. International dispersal of dengue through air travel: importation risk for Europe. PLoS Negl Trop Dis. 2014;8:e3278.

66. Grout A, Howard N, Coker R, Speakman EM. Guidelines, law, and governance: disconnects in the global control of airline-associated infectious diseases. Lancet Infect Dis. 2017;17:e118-22.

67. Kollars TM Jr, Kollars PG, Hulsey B. Reducing the risk to marine ports from invasive mosquito species, zika, dengue, chikungunya viruses and filariasis. Int J Med. 2016:4:70-3.

68. Service MW. Mosquito ecology: field sampling methods. 2nd ed. London: Elsevier Applied Science; 1993.

69. White F. The vegetation of Africa: a descriptive memoir to accompany the Unesco/AETFAT/UNSO vegetation map of Africa. Paris: Unesco; 1983.

70. Silver JB. Mosquito ecology: field sampling methods. 3rd ed. London: Springer; 2008

71. Brisco KK, Cornel AJ, Lee Y, Mouatcho J, Braack L. Comparing efficacy of a sweep net and a dip method for collection of mosquito larvae in large bodies of water in South Africa. F1000Res. 2016:5:713.

72. Edwards FW. Culicine adults and pupae. In: Mosquitoes of the Ethiopian region. Volume III. London: British Museum (Nat. Hist.); 1941.

73. Service MW. Handbook to the Afrotropical toxorhynchitine and culicine mosquitoes, excepting Aedes and Culex. London: British Museum (Natural History); 1990
74. Choi KS, Coetzee M, Koekemoer LL. Simultaneous identification of the Anopheles funestus group and Anopheles longipalpis type C by PCR-RFLP. Malar J. 2010;9:316.

75. Lee Y, Marsden CD, Norris LC, Collier TC, Main BJ, Fofana A, et al. Spatiotemporal dynamics of gene flow and hybrid fitness between the $M$ and $\mathrm{S}$ forms of the malaria mosquito, Anopheles gambiae. Proc Natl Acad Sci USA. 2013:110:19854-9.

76. Lee Y, Olson N, Yamasaki Y, Chang A, Marsden C, Ouledi A, et al. Absence of kd resistance alleles in the Union of the Comoros, East Africa. F1000Res. 2015:4:146.

77. Cornel AJ, McAbee RD, Rasgon J, Stanich MA, Scott TW, Coetzee M. Differences in extent of genetic introgression between sympatric Culex pipiens and Culex quinquefasciatus (Diptera: Culicidae) in California and South Africa. J Med Entomol. 2003:40:36-51.

78. The R Project for Statistical Computing. Avialable at http://www.r-project.org/. Accessed 10 Dec 2017.

79. Shannon CE. Prediction and entropy of printed English. Bell System Tech J. 1951:30:50-64.

80. Spellerberg IF, Fedor PJ. A tribute to Claude Shannon (1916-2001) and a plea for more rigorous use of species richness, species diversity and the 'Shannon-Wiener' Index. Global Ecol Biogeog. 2003;12:177-9.

81. Horn H. Measurement of "overlap" in comparative ecological studies. Am Nat. 1966:100:419-24.

82. Wolda H. Similarity indices, sample size and diversity. Oecologia. 1981;50: 296-302.

83. Christian KA, Iuliano AD, Uyeki TM, Mintz ED, Nichol ST, Rollin P, et al. What we are watching - top global infectious disease threats, 2013-2016: An update from CDC's global disease detection operations center. Health Secur. 2017:15:453-62.

84. Gould E, Pettersson J, Higgs S, Charrel R, de Lamballerie X. Emerging arboviruses: Why today? One Health. 2017;4:1-13.

85. Chan M. Address to the sixty-fifth World Health Assembly. In: Sixty-fifth World Health Assembly. Geneva, Switzerland. Avaible at http://www.who. int/dg/speeches/2012/wha_20120521/en/. Accessed on 7 Mar 2018.

86. Tawe L, Ramatlho P, Waniwa K, Muthoga CW, Makate N, Ntebela DS, et al. Preliminary survey on Anopheles species distribution in Botswana shows the presence of Anopheles gambiae and Anopheles funestus complexes. Malar J. 2017; 16:106.

87. Mbokazi MF. Ecology of breeding sites and insecticide resistance of the potential malaria vectors in Mpumalanga Province, South Africa. Johannesburg: University of the Witwatersrand, Faculty of Health Sciences; 2015.

88. Govere J, Durrheim D, Coetzee M, Hunt R, La Grange J. Captures of mosquitoes of the Anopheles gambiae complex (Diptera: Culicidae) in the Lowveld region of Mpumalanga Province, South Africa. Afr Entomol. 2000:8:91-9.

89. Ngomane L, Nkosi BG, Booman M, la Grange JJP, Koekemoer LL, Maharaj R. The distribution and abundance of species of the Anopheles funestus group (Diptera: Culicidae) in Mpumalanga Province, South Africa. Afr Entomol. 2007;15:221-4.

90. Steyn JJ, Rose Innes R, Schultz KH. A Culicine mosquito survey of the upper Limpopo River Valley. J Ent Soc S Afr. 1955;18:238-46.

91. Schultz KH, Steyn JJ, Rose-Innes RA. Culicine mosquito survey of the Kruger National Park. Koedoe. 1958;1:189-200.

92. van der Linde de KTC, Hewitt PH, van Pletzen R, Kok DJ, Fourie S, Mostert DJ, Nel A. Species richness and relative abundance of female mosquitoes at a site in the western Orange Free State. J Ent Soc S Afr. 1982:45:57-67.

93. Cornel AJ, Holeman J, Nieman CC, Lee Y, Smith C, Amorino M, et al. Surveillance, insecticide resistance and control of an invasive Aedes aegypti (Diptera: Culicidae) population in California. F1000Res. 2016;5:194 